These are :-

I. That it is sometimes difficult to adjust the angle of the film so as to get the best light on it.

2. It is impossible to vary the distance of the film from the mouth so as to use both loud and faint sounds.

3. There is no means of adjusting the tension of the film.

My phoneidoscope, which is free from these defects, and which I have found to work exceedingly well, simply consists of the hand and some soap-suds. The forefinger and thumb being bent so as to form a circle, a soap film is drawn across them with the other hand. By turning the wrist, the angle which the film makes with the direction of the light can be accurately adjusted.

A motion of the elbow alters the distance from the film to the mouth, and by slightly separating or bringing together the finger and thumb, the tension of the film can be exactly regulated so as to give any degree of sensitiveness that may be desired.

The extra delicacy obtained by this adjustment much more than counterbalances the absence of the tube and mouthpiece. Pixholme, July 30 J. E. H. GORDON

\section{Spectrum of the Electric (Jablochkoff) Light}

I would suggest that when your readers visit Paris they should take their pocket spectroscopes. They will find a very interesting spectrum in the electric lamps now being used for lighting some of the principal public places in the city. One might have expected to have found from the brilliant spark inclosed in a white opaline globe a continuous spectrum such as is afforded by the voltaic arc. But the contrary is the case. The Jablochkoff candle now in use in Paris, even when viewed by one of Browning's small pocket instruments, presents a very complicated and highly interesting spectrum. I had no chart with me for comparison, nor did I, as I intended subsequently, make even a rough record of the spectrum; but speaking from memory, I may say that several lines in the blue and green were very marked and distinct, and, in fact, the whole spectrum was traversed by bright and dark lines. I thought, probably, some of these dark lines might be due to absorption by the white opaline glass globe, but I have tested several specimens of this white glass, and I find it does not alter in any way (except by generally reducing its brilliancy) a continuous spectrum, nor does it change the character of the solar spectrum. We must, then, turn to the light itself and to the atmosphere surrounding it for the cause of these phenomena. I believe that in a chemical sense there is no difference between the ordinary electric arc between the carbon points and the arc of the Jablochkoff candle, except that between the carbon points of the latter is a rod of kaolin, which has, I think, a calcium base. This kaolin is intensely heated by the current, and is volatised at the same rate as the carbon rods by the alternative current which this form of candle requires. The light, therefore, is a combination of the electric and the lime light, the current taking the place of the oxy-hydrogen elements. The surrounding atmosphere will be the same in both cases, but the products of combustion will obviously be different, and partly so from the composition of the kaolin. Still, I confess that I camnot suggest the cause of this complicated spectrum, and I hope that some observers who have more accurate means and more ex. perience will give us the rationale of the phenomena.

I may say that there is not at present any Jablochkoff candles to be seen in use in this country, but in the course of two or three weeks they will be introduced into a large establishment, where excellent means of observation will be afforded.

Royston House, Tottenham, July 27

E. WALKER

P.S.-Since forwarding the above I have observed the Loutin light now on view at the Gaiety Theatre. The spectrum is somewhat similar to that of the Jablochlioff light, but much less distinct. This is probably owing to the circumstance that at the Gaiety the arc is inclosed in a small opaline globe, which is itself encased in an ordinary ground glass lanthorn (the proper lamps came to grief in transit), this diffusive ground glass causing, by overlapping, the indistinctness. Still there are absorption bands and some remarkable bright lines, which, with my small pocket instrument, I will not attempt to define. Nor, as it is a matter for careful observation, will I speculate further than to suggest-seeing that the Loutin light is from the carbon points only-- that the white opaline glass may exercise a selective power over the spectrum given by this high state fof incandescence which it does not in ordinary cases, and may give us also, to an extent, the actual, wave due to a particular element rather than its obscuration. If so the Loutin light should differ somewhat from the Jablochkoff light, being deficient of the kaolin.

E. W.

\section{The Meteor Showers of July}

THE prominent shower of Aquarid's mentioned in my letter in NATURE, vol. xviii. p. 356 , had become extremely feeble on July $3 \mathrm{I}$ and August $\mathrm{r}$, for of 136 shooting stars seen on those nights only three or four were conformable to that radiant point which, from a careful re-examination of all the paths recorded from it, is situated exactly at $34 \mathrm{I}^{\circ}-13^{\circ}$, near $\delta$ Aquarii (from fifty-four meteors).

Between July 26 and August 2403 shooting stars were recorded here, of which no less than sixty-three (including one perfectly stationary) belonged to a very sharply-defined radiant near $\chi$ Persei, at $32^{\circ}+53^{\circ}$. Fourty-four of these were noted on the three nights, July 30-3I and August I, when the shower appeared to attain its full intensity. The meteors were very swift with short paths (of about $7^{\circ}$ ), and almost invariably left streaks of $3^{\circ}$ or $4^{\circ}$. They were shorter and less bright than the August Perseids at $43^{\circ}+5^{\circ}$, and in strong contrast to the long, slow meteors of Aquarids seen on the few preceding nights. This very rich stream at $32^{\circ}+53^{\circ}$ has escaped previous detection, for, being near the date and position of the August Perseids, there can be no doubt that its meteors have in past years been attributed to that well-known shower, and given it an undue extension of period. The two radiants are, however, quite distinct, and it is now easy to explain the statements of some observers that there are many Perseids visible during the latter part of July. I believe that but few of the old.Perseids can be seen before August 6 or 7. My own observations this year show that only seven or eight were seen before August 2, though I watched that region in which the radiant lies very carefully, and noted 400 meteors amongst the constellations there!

Thus at the end of July we may expect two special meteor showers: one of Aquarids, at $341^{\circ}-13^{\circ}$, the other of Perseids, $32^{\circ}+53^{\circ}$. The former comes to a maximum two or three nights earlier than the latter, which may be called the "Perseid's II.," in order to distinguish them from the old Perseia's of Heis.
Ashleydown, Bristol, August 3
W. F. DENNING

The Rainfall of Brazil and the Sun-Spots

AN examination of the scanty records of rainfall obtainable in Brazil proves that the relation between rainfall and sun-spots, which has been pointed out in India by Dr. Hunter and others, holds good for the inter-tropical portion of Brazil.

The only stations from which $I$ have been able to obtain records for a series of years are the city of Fortaleza (better known in Europe as Ceará), in latitude $3^{\circ} 42^{\prime} \mathrm{S}$., and Rio de Janeiro, in latitude $23^{\prime} \mathrm{S}$. The rainfall of these two stations is shown in series in the following table:-

\begin{tabular}{|c|c|c|c|}
\hline $\begin{array}{l}\text { Series of Years in the Cycle } \\
\text { of Eleven Years. }\end{array}$ & $\begin{array}{l}\text { Average rela- } \\
\text { tive Annual } \\
\text { Number of } \\
\text { Sun-Spots, } \\
\text { I8II-1875. }\end{array}$ & $\begin{array}{l}\text { Mean Annual } \\
\text { Rainfali of } \\
\text { Ceará, } \\
\text { x } 849-1877\end{array}$ & $\begin{array}{l}\text { Mean Annual } \\
\text { Rainfall of } \\
\text { Riode Janeiro, } \\
1851-1877 .\end{array}$ \\
\hline 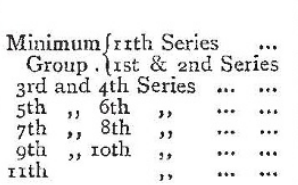 & $\begin{array}{l}\text { I6.3 } \\
\text { I0.8 } \\
48 \cdot 6 \\
48 \cdot 6 \\
88 \cdot 3 \\
65 \cdot 3 \\
38 \cdot 5 \\
16 \cdot 3\end{array}$ & 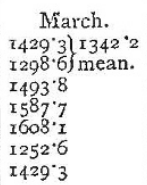 & 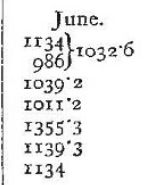 \\
\hline
\end{tabular}

The northern provinces of Brazil outside of the Amazon valley, and notably that of Ceará, are subject to severe and prolonged droughts, of which that of 1877 is one of the most terrible on record. The annals of Ceará make mention of thirty years of drought since I7xr, many of which, however, were only partial or slight, and many of which occurred in groups of consecutive years, there being one group of five dry years, another of four, and four groups of two years each. Twelve notable floods are also recorded since 1776 . The dronghts and floods are distributed as follows, among the groups of the years of the sun-spot cycle, proposed by Dr. Hunter :- 